\title{
Comparison of the Tidal Signatures in Sporadic E and Vertical Ion Convergence Rate, Using FORMASAT-3/COSMIC Radio Occultation Observations and GAIA Model
}

\section{Sahar Sobhkhiz-Miandehi ( $\nabla$ sobhkhizsahar@yahoo.com )}

gfz german research centre for geosciences https://orcid.org/0000-0002-8668-9042

Yosuke Yamazaki

GFZ: Deutsches Geoforschungszentrum Potsdam

\section{Christina Arras}

GFZ: Deutsches Geoforschungszentrum Potsdam

\section{Yasunobu Miyoshi}

Kyushu University

Hiroyuki Shinagawa

national institute of information and communication technology

\section{Full paper}

Keywords: Sporadic E, Es, wind shear, solar tide, lunar tide, GAIA, radio occultation

Posted Date: November 10th, 2021

DOI: https://doi.org/10.21203/rs.3.rs-1029914/v1

License: (c) (i) This work is licensed under a Creative Commons Attribution 4.0 International License.

Read Full License 
1 Title: Comparison of the Tidal Signatures in Sporadic $\mathbf{E}$ and Vertical Ion

2 Convergence Rate, Using FORMASAT-3/COSMIC Radio Occultation Observations

3 and GAIA Model

4 Author\#1: Sahar Sobhkhiz-Miandehi, GFZ German Research Centre for Geosciences-

5 Potsdam-Germany, \& Faculty of Science-University of Potsdam- Potsdam- Germany,

6 sahar@gfz-potsdam.de

7 Author\#2: Yosuke Yamazaki, GFZ German Research Centre for Geosciences- Potsdam-

8 Germany, yamazaki@gfz-potsdam.de

9 Author\#3: Christina Arras, GFZ German Research Centre for Geosciences-Potsdam-

10 Germany, arras@gfz-potsdam.de

11 Author\#4: Yasunobu Miyoshi Kyushu University-Fukuoka-Japan,

12 miyoshi.yasunobu.527@m.kyushu-u.ac.jp

13 Author\#5: Hiroyuki Shinagawa, National Institute of Information and Communications

14 Technology-Tokyo-Japan, sinagawa@nict.go.jp

15 Corresponding author: Sahar Sobhkhiz-Miandehi 


\section{Abstract}

17 Sporadic E or Es is a transient phenomenon where thin layers of enhanced electron

18 density appear in the ionospheric E region (90-120 km altitude). The neutral wind shear

19 caused by atmospheric tides can lead ions to converge vertically at E-region heights and

20 form the Es layers. This research aims to determine the role of atmospheric solar and

21 lunar tides in Es occurrence. For this purpose, radio occultation data of FORMASAT-

223 /COSMIC have been used, which provides complete global coverage of Es events.

23 Moreover, GAIA model simulations have been employed to evaluate the vertical ion

24 convergence induced by solar tides. The results show both migrating and non-migrating

25 solar tidal signatures and the semidiurnal migrating lunar tidal signature in Es occurrence.

26 The seasonal variation of the migrating solar tidal components of Es is in good agreement

27 with those in the vertical ion convergence derived from GAIA. Furthermore, some non-

28 migrating components of solar tides, including semidiurnal westward wavenumbers 1 and

293 and diurnal eastward wavenumbers 2 and 3, also significantly affect the Es occurrence

30 rate. 


\section{$31 \quad$ Keywords}

32 Sporadic E, Es, wind shear, solar tide, lunar tide, GAIA, radio occultation

\section{Introduction}

34 Thin layers of enhanced electron density, which are detected in the lower thermosphere

35 at the altitude range of 90 to $120 \mathrm{~km}$, are referred to as Sporadic E and abbreviated as Es

36 (Haldoupis, 2011; Mathews, 1998; Whitehead, 1989). This transient phenomenon

37 frequently occurs at mid and low latitudes (Christakis et al., 2009; Haldoupis, 2012;

38 Haldoupis et al., 2007), mainly during the daytime in the summer hemisphere (Arras et

39 al., 2010). Es layers have been the subject of many studies since the mid-twentieth century

40 (e.g., Macleod, 1966; Whitehead, 1961, 1970, 1989) due to their impact on radio wave

41 propagation in communication and navigation systems.

42 Wind shear theory is the most commonly accepted physical mechanism for midlatitude

43 Es layer formation (Haldoupis \& Pancheva, 2002; Haldoupis, 2011). According to wind

44 shear theory, metallic ions such as $\mathrm{Fe}^{+}, \mathrm{Na}^{+}$, and $\mathrm{Ca}^{+}$in the ionosphere dynamo region,

45 influenced by vertical shears of horizontal wind and the Earth's magnetic field, will converge vertically to a thin layer of ionization (Axford \& Cunnold, 1966; Haldoupis, 
48 The wind shears in the lower thermosphere are mainly produced by atmospheric tides,

49 including solar /lunar tides with the period of a solar /lunar day and its harmonics. Solar

50 tides are known to be the primary source of vertical shears in the neutral wind (Haldoupis,

51 2012); hence a solar tidal signature is expected to be seen in the Es occurrence. Numerous

52 studies have focused on the solar tidal signature in the Es layer. For example, Mathews

$53 \&$ Bekeny (1979) demonstrated that the vertical motion of Es layers is consistent with

54 diurnal and semidiurnal tides in the neutral atmosphere. Arras et al. (2009) presented

55 semidiurnal solar tidal signatures in Es occurrence rate (EsOR) at northern hemisphere

56 midlatitude $\left(50^{\circ}-55^{\circ} \mathrm{N}\right)$. They compared EsOR with meteor radar wind measurements and

57 found a strong relationship between semidiurnal tides in EsOR and vertical shear of zonal

58 wind. Christakis et al. (2009) studied the midlatitude Es layer seasonal variation and

59 indicated diurnal tide influence on Es at altitudes below $110 \mathrm{~km}$ and semidiurnal tide

60 dominance above that altitude. Oikonomou et al. (2014) also showed that a semidiurnal

61 tide-like periodicity dominates Es layers. Terdiurnal and querterdiurnal tidal signatures in

62 Es occurrence rate are also indicated in other publications (e.g., Haldoupis \& Pancheva, 
63 2006; Fytterer et al., 2013; Jacobi et al., 2019). Recently, Liu et al. (2021) revealed a

64 wavenumber 4 pattern in Es occurrence rate at mid and low latitudes formed by eastward

65 propagating non-migrating diurnal tide with zonal wavenumber 3 , and a similar feature

66 was detected in the vertical shear of the zonal wind.

67 Shinagawa et al. (2017) calculated the vertical ion convergence rate using GAIA

68 (Ground-to-topside model of Atmosphere and Ionosphere for Aeronomy) simulations to

69 show how the geographical and seasonal variations of wind shears are consistent with

70 those in EsOR. Some previous studies have utilized GPS radio occultation (RO)

71 measurements and combined them with winds from different models such as HWM07

72 (Horizontal Wind Model 2007), WACCM (the Whole Atmosphere Community Climate

73 Model), and GAIA, to show neutral wind shear correspondence with Es (e.g., Chu et al.,

74 2014; Liu et al., 2018; Qiu et al., 2019; Yeh et al., 2014). However, it is not yet fully

75 understood precisely which components of tides contribute to Es layer formation. This

76 paper provides a tidal spectrum of Es occurrence rate using GPS radio occultation

77 measurements and then compares them with tidal spectra of vertical ion convergence rate

78 using GAIA model simulations. 
79 Some investigations have been done on the lunar tide influences on Es using ground-

80 based observations (e.g., Matsushita, 1952, 1957, 1967; Stening, 1999; Tarpley \&

81 Matsushita, 1971, 1972), but none of them have provided a global picture of lunar tidal

82 signature in the Es occurrence. The present study will look over global lunar tidal

83 variations of Es occurrence using GPS radio occultation measurements.

84 Apart from atmospheric tides, planetary waves can also contribute to wind shear

85 formation in the lower thermosphere. Some studies have suggested planetary wave effects

86 on Es events (e.g., Haldoupis \& Pancheva, 2002; Pancheva et al., 2003; Haldoupis et al.,

87 2004; Voiculescu et al., 1999), but planetary waves are not in the scope of the current

88 paper. Interested readers can refer to the articles mentioned above.

\section{FORMOSAT-3/COSMIC radio occultation data}

90 For many years, Es events were mainly observed by ionosonde and sometimes in situ

91 techniques (Mathews, 1998; Matsushita, 1962; Whitehead, 1989). In the past two decades,

92 many studies have benefited from the new GPS radio occultation methodology to obtain

93 the global distribution of Es layers (Arras et al., 2008; Hocke et al., 2001; Wu et al., 2005).

94 GPS radio occultation is a satellite remote sensing technique in which GPS signals are 
received by a low earth-orbiting satellite (LEO) after traveling through the atmosphere.

96 Due to the atmospheric refractive index, the signals are bent on their way. This bending

97 angle is the key observation to obtain information of the ionosphere and neutral

98 atmosphere (Arras, 2010).

99 FORMOSAT-3/COSMIC (FORMOsa SATellite mission-3 / Constellation Observing

100 System for Meteorology, Ionosphere and Climate) consists of six LEO satellites, launched

101 on April 2006. At the altitude of 80 to $130 \mathrm{~km}$, scintillations are observed in SNR and

102 phase measurements of FORMOSAT-3/COSMIC radio occultation signals, usually

103 caused by Es layers. Signal phase differences, ionospheric excess phase, and SNR values

104 are used in different literature to extract Es events from GPS-RO measurements (Hocke

105 et al., 2001; Wu et al., 2005). EsOR in this study is derived from the signal-to-noise ratio

106 (SNR) profiles of GPS L1 signal of the level $1 \mathrm{~b}$ atmPhs data product. Limiting thresholds

107 has been set empirically to SNR values, and Es is defined as scintillations with SNR

108 standard deviation more than 0.2 in a narrow altitude range. The method details can be

109 found in Arras \& Wickert (2018). Our investigations are based on FORMOSAT-

$1103 /$ COSMIC radio occultation data of the years 2007 to 2017. 


\section{GAIA model simulation data analysis}

112 GAIA is a whole atmosphere model that has been developed by coupling three existing

113 models: A whole atmosphere general circulation model (GCM) for deriving atmospheric

114 neutral density, velocity, and temperature; an ionospheric model for ion density, ion, and

115 electron temperature, and electric conductivity; and an electrodynamics model for the

116 electric field (Jin et al., 2011). In the present study, the temperature and composition of

117 the neutral atmosphere and the neutral wind velocity are obtained from the GAIA model

118 with a grid spacing of $2.8^{\circ}$ longitude by $2.8^{\circ}$ latitude, 0.2 scale height, and a time

119 resolution of 1 hour. We have analyzed GAIA simulation data for the years 2007 to 2017 .

120 Neglecting diffusion, electric field force, and vertical component of neutral wind velocity,

121 the vertical ion drift velocity $\mathrm{w}_{\mathrm{i}}$ can be written as follows (Mathews, 1998):

$$
\mathrm{W}_{\mathrm{i}}=\frac{\mathrm{r} \cos \mathrm{I}}{1+\mathrm{r}^{2}} \mathrm{U}+\frac{\cos \mathrm{I} \sin \mathrm{I}}{1+\mathrm{r}^{2}} \mathrm{~V}
$$

123 where $\mathrm{I}$ is the Earth's magnetic field dip angle, $\mathrm{U}$ and $\mathrm{V}$ are magnetic eastward and

124 southward neutral wind velocity, and $\mathrm{r}$ is the ratio of the ion-neutral collision frequency

to the ion gyrofrequency. In the lower E region $(90-115 \mathrm{~km}$ altitude), $r>>1$ (Richmond, 
127 component in causing vertical ion motion and, as a result, the Es layer formation

128 (Haldoupis, 2012).

129 Using geographical neutral wind velocities, $U$ and $V$ used in equation (1) are expressed

130 as follows (Qiu et al., 2019):

$$
\left\{\begin{array}{l}
U=U^{\prime} \cos D-V^{\prime} \sin D \\
V=V^{\prime} \cos D+U^{\prime} \sin D
\end{array}\right.
$$

132 where $\mathrm{U}^{\prime}$ and $\mathrm{V}^{\prime}$ are zonal and meridional wind velocities, respectively. $\mathrm{U}^{\prime}$ and $\mathrm{V}^{\prime}$ are

133 derived from the GAIA model, and D is the Earth's magnetic field declination angle,

134 derived from International Geomagnetic Reference Field (IGRF; Finlay et al., 2010). We

135 calculate the average vertical ion convergence rate (VIC) and assume only positive VICs

136 lead to Es layer formation. Therefore, we can write VIC as (Shinagawa et al., 2017):

$$
\mathrm{VIC}=\left\{\begin{array}{c}
-\frac{\partial \mathrm{w}_{\mathrm{i}}}{\partial \mathrm{z}}, \quad-\frac{\partial \mathrm{w}_{\mathrm{i}}}{\partial \mathrm{z}}>0 \\
0, \quad-\frac{\partial \mathrm{w}_{\mathrm{i}}}{\partial \mathrm{z}}<0
\end{array}\right.
$$

\section{$138 \quad$ Results}

\section{Es occurrence rate analysis}

140 The Es occurrence rate is maximum in midlatitude summer hemispheres (Arras et al.,

1412008 ), and in the latitude range of $40^{\circ}$ to $60^{\circ}$ south and north, tidal signatures are clearly

142 seen. Therefore, we have analyzed two local summer periods of FORMOSAT-3/COSMIC 
143 radio occultation data: one is for the period of June, July, and August of years 2007 to

1442017 at the latitude range of $40^{\circ}$ to $60^{\circ}$ north, and the other is December, January, and

145 February of years 2007 to 2017 at the latitude range of $40^{\circ}$ to $60^{\circ}$ south. Binning the

146 data into $1 \mathrm{~km}$ altitude by 1 -hour local time grids, altitude-local time cross-sections of the

147 EsOR for the northern hemisphere summer is presented in Figure 1. Maximum values of

148 EsOR reach up to $13 \%$ in northern hemisphere summer.

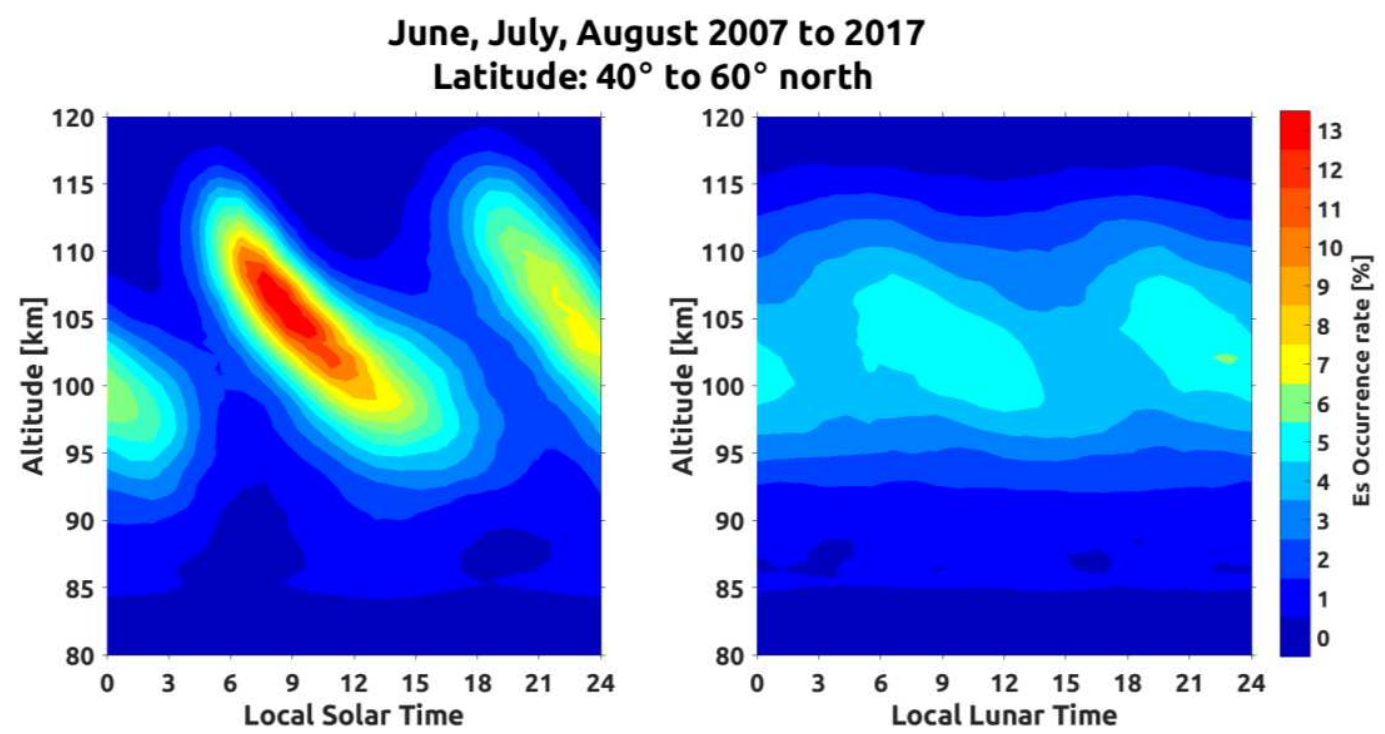

Figure 1 Mid-latitude EsOR variations during northern hemisphere summer with solar local time (left) and lunar local time(right) at different altitudes

149 A descending structure of EsOR with local solar time (LST) and local lunar time (LLT)

150 is visible. EsOR variations with LST and LLT reveal a semidiurnal pattern at about 95-

$151115 \mathrm{~km}$ altitude. The same applies to southern hemisphere summer shown in Figure 2.

152 However, the maximum values of EsOR reach only $6.5 \%$ in the southern hemisphere, 
153 which is almost half of that in the northern hemisphere.

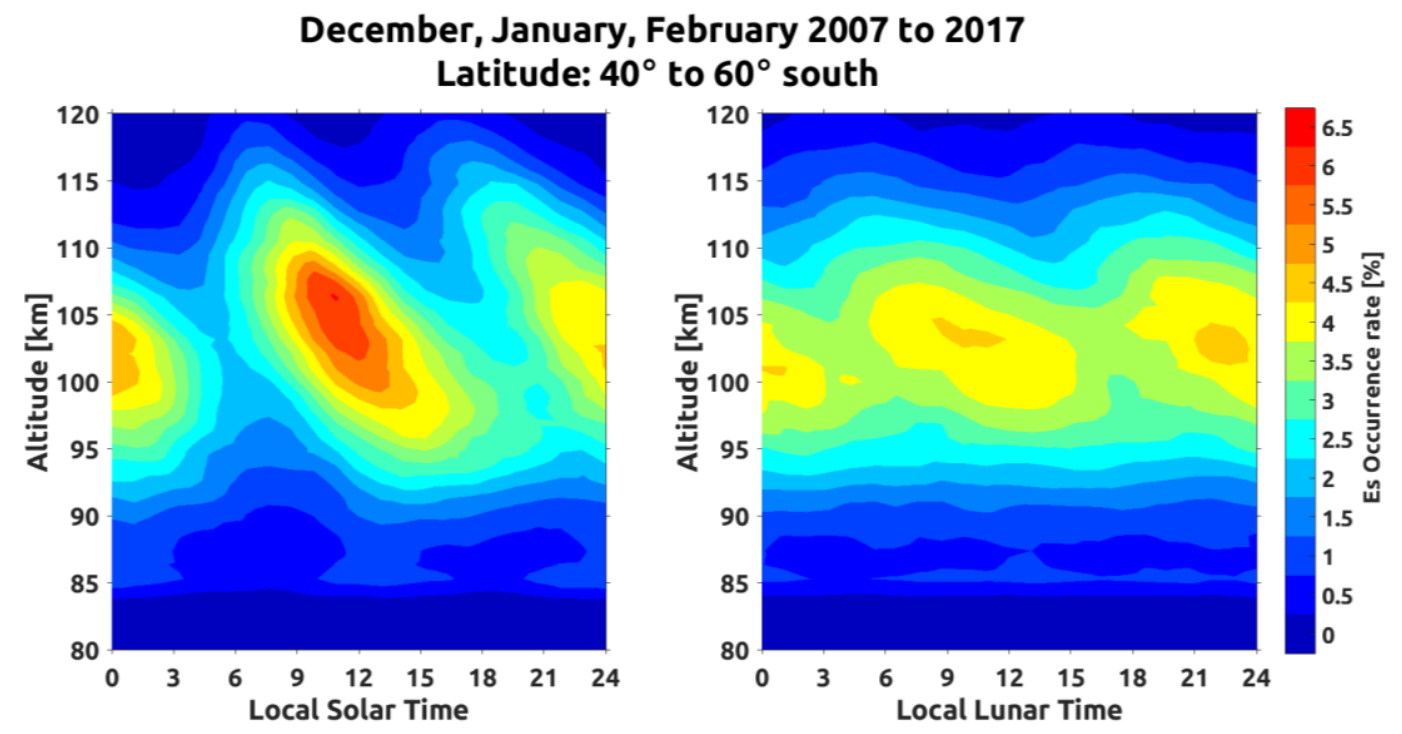

Figure 2 Mid-latitude EsOR variations during southern hemisphere summer with solar local time (left) and lunar local time(right) at different altitudes

154 Tidal modulations at periods of 12 hours are identified in the EsOR, with the peaks around

1559 and 21 local time in the northern hemisphere. This confirms previous studies on solar

156 and lunar tidal signature detection in northern hemisphere Es layers (e.g., Matsushita,

157 1962; Arras et al., 2009). The phase of solar and lunar tidal signatures are slightly shifted

158 in southern hemisphere EsOR.

159 Spatio-temporal characteristics of EsOR can be quantified using the least-square fitting

160 method. This method estimates the amplitude and phase of tides at a specific frequency

161 and zonal wavenumber, which enabels us to seprate migrating and non-migrating tidal

162 components. We map the data in the frequency-wavenumber domain, and EsOR 
measurements can be expressed as:

164

$$
\mathrm{EsOR}=\sum_{\mathrm{n}, \mathrm{s}}\{\mathrm{A}(\mathrm{n}, \mathrm{s}) \cos [2 \pi(\mathrm{nt}+\mathrm{s} \lambda)]+\mathrm{B}(\mathrm{n}, \mathrm{s}) \sin [2 \pi(\mathrm{nt}+\mathrm{s} \lambda)]\}
$$

165 where $\mathrm{n}$ is frequency, $\mathrm{s}$ is the wavenumber, $\mathrm{t}$ is the normalized time of the day, and $\lambda$ is

166 the normalized longitude (Lühr \& Manoj, 2013). In order to examine tidal components in

167 EsOR, we have limited the data to the altitude range of $95-115 \mathrm{~km}$, in which the solar and

168 lunar tidal signatures are dominant and binned them in $10^{\circ}$ longitude by 1 -hour local

169 time grids. Afterward, frequency-wavenumber analyses have been performed on the data

170 similar to the method suggested in Lühr \& Manoj (2013). Tides with the periods of 24h,

$17112 \mathrm{~h}, 8 \mathrm{~h}, 6 \mathrm{~h}$ respectively are represented by $\mathrm{n}=1,2,3,4$ and are referred to as diurnal,

172 semidiurnal, terdiurnal, and quarterdiurnal tides (Forbes et al., 2008).

173 To describe different tidal components, we use the following terminology: tidal periods

174 are represented by $\mathrm{D}, \mathrm{S}, \mathrm{T}$, and $\mathrm{Q}$, which are respectively corresponding to diurnal,

175 semidiurnal, terdiurnal, and quarterdiurnal tides. Eastward $(\mathrm{s}<0)$ and westward $(\mathrm{s}>0)$

176 propagating tides are represented by $\mathrm{E}$ and $\mathrm{W}$. These two letters are followed by an integer

177 representing the zonal wavenumber. For example, DW1 means diurnal westward 

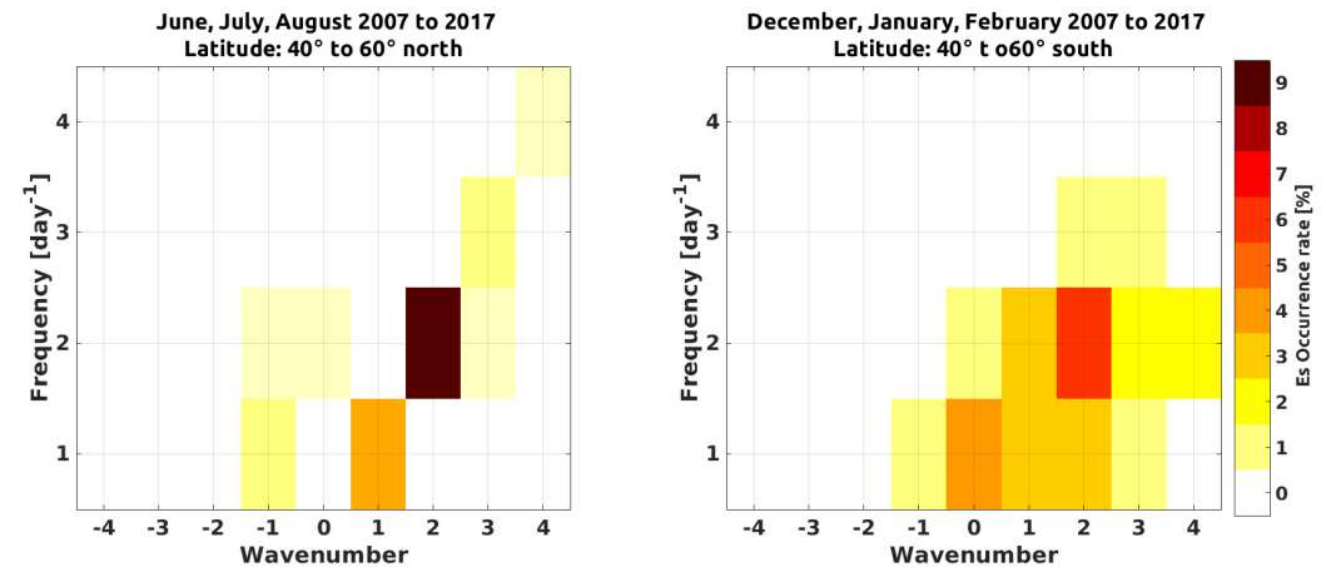

Figure 3 Solar tidal spectra of mid-latitude EsOR amplitude during northern hemisphere summer (left) and southern hemisphere summer (right)

180 The tidal spectra shown in Figure 3 correspond to the amplitude of solar tides during local

181 summers in northern and southern midlatitudes. Different migrating and non-migrating

182 tidal components are seen; among which the SW2 component has the highest amplitude

183 in both summer hemispheres. For the northern hemisphere, DW1 is in second place;

184 however, for the southern hemisphere, D0 is the second component with a high amplitude.

185 Figure 4 shows the tidal spectra of lunar tides signature in EsOR. Unlike solar tides, lunar

186 tidal spectra show that only SW2 component is dominant in the summer hemispheres,

187 and other tidal components are relatively small. 

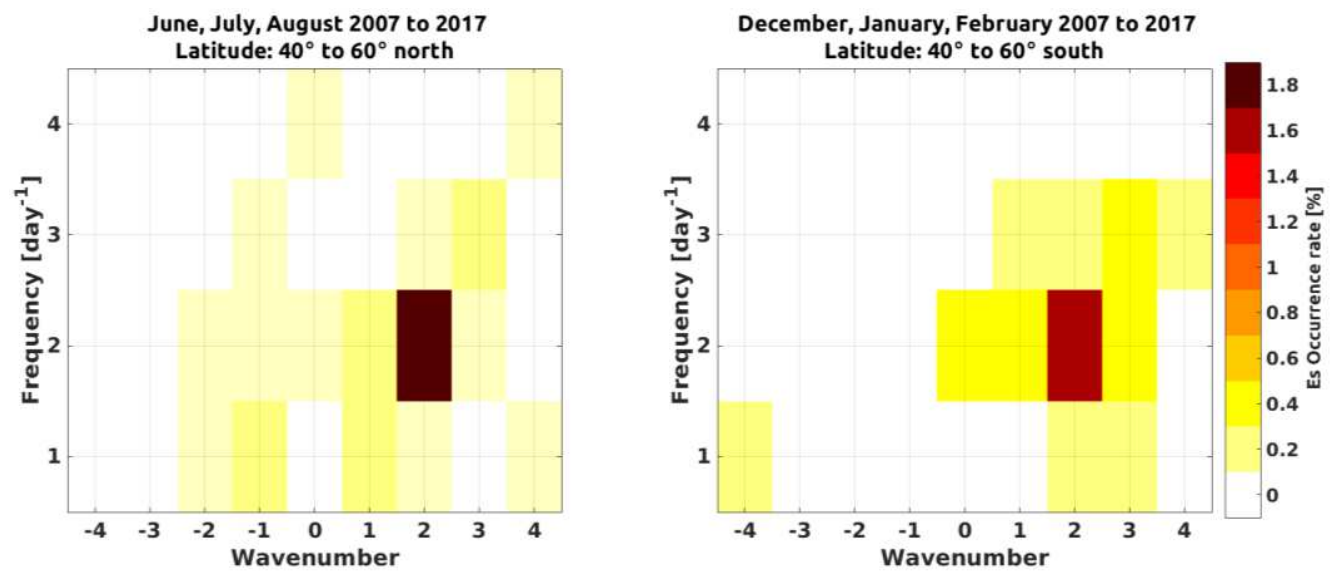

Figure 4 Lunar tidal spectra of mid-latitude EsOR during northern hemisphere summer (left) and southern hemisphere summer (right)

\section{Comparison of VIC and EsOR}

189 In order to compare tidal components of VIC and EsOR, tidal analysis has been performed on 11-year VIC and EsOR data sampled around 100, 105, 110, 115km altitude.

191 We studied the latitudinal variation of different tidal components of VIC and EsOR on a

192 month-to-month basis at different altitudes. By calculating the correlation coefficients

193 between each tidal component of VIC and EsOR at different altitudes, we realized that

194 the altitude in which EsOR and VIC have the best correlation, vary for each component.

195 For example, Figure 5 reveals DW1 component of EsOR and VIC over different months

196 and latitude bands at different altitudes. The seasonal variation of DW1 component of

197 EsOR in different latitudes at $105 \pm 5 \mathrm{~km}$ seems more similar to that of VIC at 110 and

$198115 \mathrm{~km}$ altitude than at $105 \mathrm{~km}$. The correlation coefficient between DW1 in EsOR at 

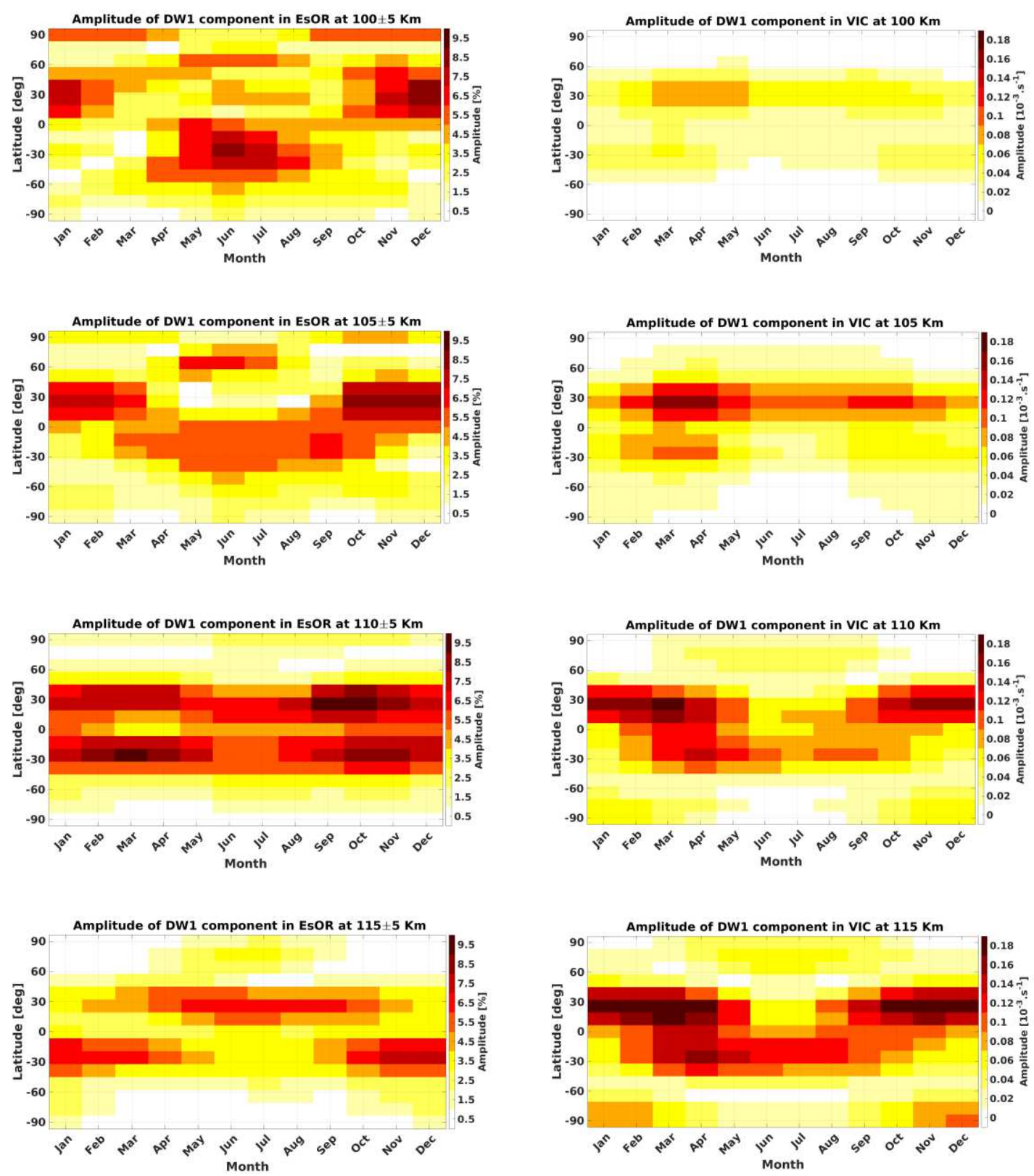

Figure 5 Month-to-month amplitude variation of DW1 component of tides in EsOR (left column) and VIC (right column) at different altitudes

201 VIC at a fixed altitude tends to correlate with the same tidal component of EsOR at a 
202 higher altitude. Also the altitudes at which VIC and EsOR tidal components correlate the

203 best, differ for different tidal components. This might be due to some inaccuracies in the

204 tides of GAIA model simulations.

205 Four different migrating and non-migrating components of EsOR tidal spectra with the

206 largest amplitude were determined, and their annual variations in different latitudes are

207 displayed in Figures 6 and 7. In addition, a comparison to the corresponding VIC tidal

208 spectra at the altitude at which they have the best correlation with each other is made in

209 those figures.

210 Among all migrating components of EsOR and VIC tidal spectra, SW2 has the highest

211 amplitude. SW2 component of northern hemisphere VIC is present in all seasons, and it

212 is dominant in midlatitude local summers for EsOR and VIC. DW1 is the second,

213 regarding its amplitude which is present throughout the year around the latitude band of

$21450^{\circ}$ south to $50^{\circ}$ north. Subsequently, TW3 and QW4 have lower amplitudes. Although

215 month-to-month and latitudinal variations of SW2 and DW1 components of EsOR are in

216 good agreement with those in VIC, seasonal variation of QW4 in EsOR is better

217 consistent with VIC in the northern hemisphere rather than southern hemisphere; and 
218 TW3 component in EsOR is not necessarily similar to that in VIC from GAIA.
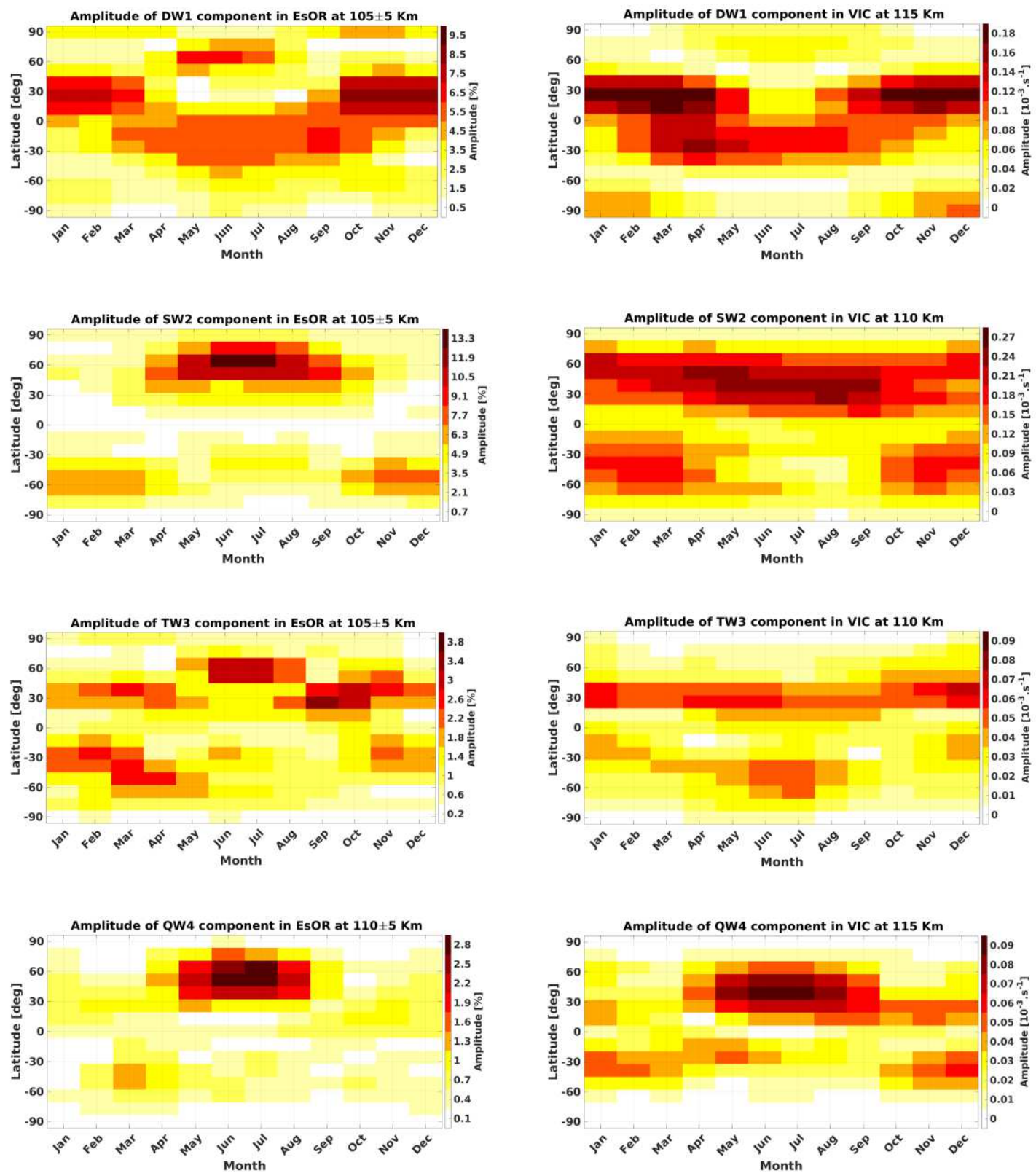

Figure 6 Month-to-month amplitude variation of migrating components of tides in EsOR (left column) and VIC (right column)

219 According to Figure 7, at high and midlatitudes, SW1 has the largest amplitude among all n on-migrating components of EsOR and VIC. In both tidal spectra, it is dominant at 

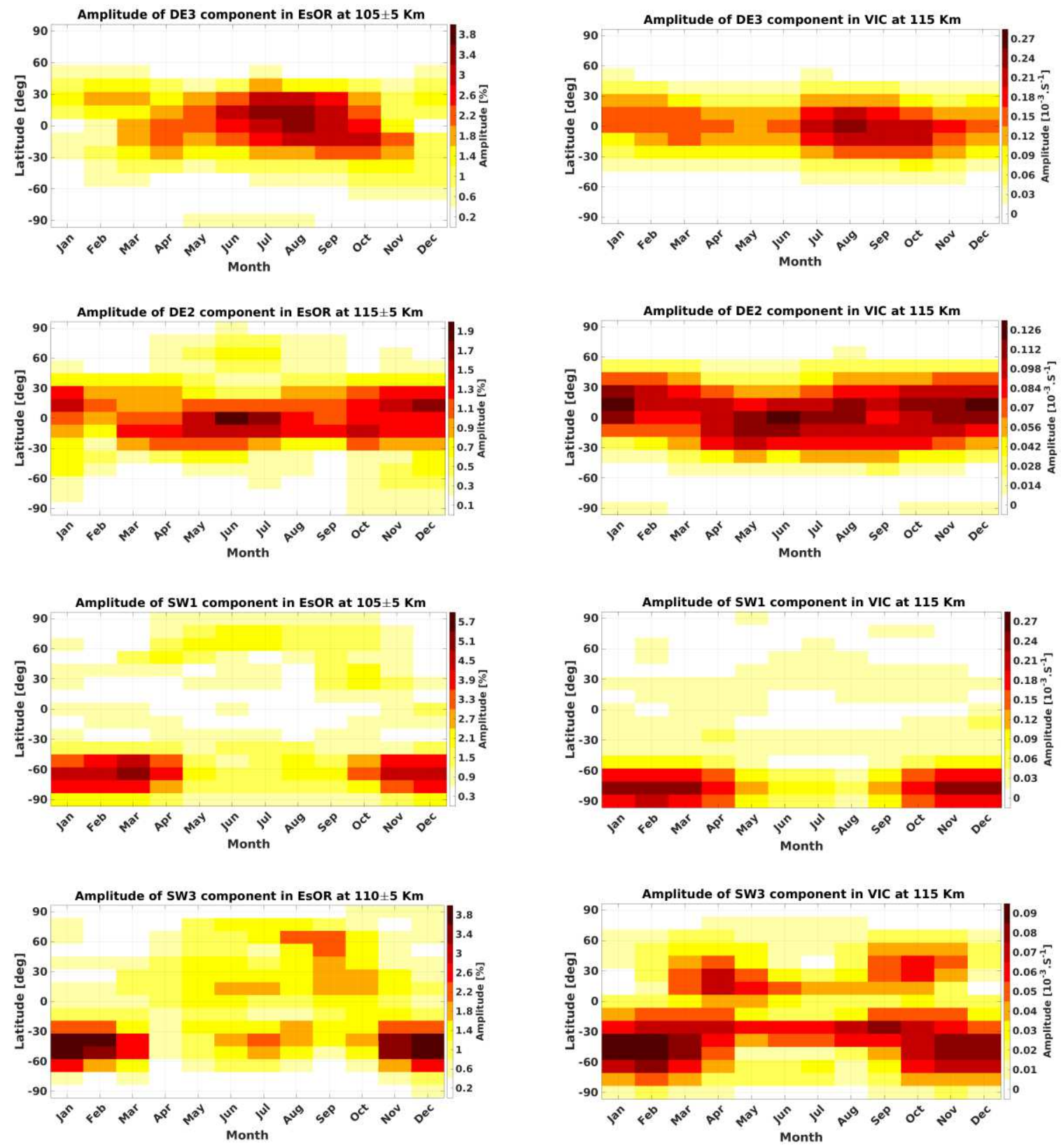

Figure 7 Month-to-month amplitude variation of non-migrating components of tides in EsOR (left column) and VIC (right column)

221 southern hemisphere high-latitude regions from November to April. The second in

222 amplitude among non-migrating components is SW3, having similar month-to-month

223 variation in EsOR and VIC only in the southern hemisphere. 
224 At low latitudes, DE2 and DE3 have the largest amplitudes in the non-migrating 225 components of EsOR and VIC. DE3 component is dominant during July to September in

226 VIC and EsOR tidal spectra. Around winter and summer solstice in low latitudes, DE2

227 component is maximum.

228 Considering only the latitudinal variation of tidal components, DE3 of EsOR and VIC are

229 in good agreement; however, their monthly variations do not match perfectly. DE2

230 component of tides follows a similar seasonal distribution in EsOR and VIC at the latitude

231 band of $30^{\circ}$ south to $30^{\circ}$ north.

\section{Discussion}

233 The results have shown that tidal components in EsOR are in agreement with those in

234 VIC. In general, the consistency between tidal components in EsOR and VIC confirms

235 that wind shears generated by tides play a major role in Es layer formation.

236 According to Figure 7, SW1 and SW3 components have the highest amplitudes among

237 all non-migrating tidal components in EsOR. This can be explained by two possible

238 mechanisms. First, SW1 and SW3 in EsOR could originate from corresponding tidal

239 components in the neutral atmosphere, produced by nonlinear interaction of the SW2 and 
240 stationary planetary wave with zonal wavenumber 1 in that region (Miyoshi et al., 2017).

241 Second, SW1 and SW3 in EsOR could be generated by stationary wave number 1

242 structure in is the Earth's magnetic field (B) and SW2 in the horizontal neutral wind

243 velocity $(\mathbf{V})$, because Es layers are formed by Lorentz force $(\mathbf{V} \times \mathbf{B})$. Seasonal variations

244 of SW1 and SW3 components of VIC at different latitudes are presented in the top panel

245 of Figure 8 . The middle panel shows the same, but for the zonal wind term in VIC

$246\left(\partial\left(\frac{r \cos I}{1+r^{2}} U\right) / \partial z\right)$. The agreement of these two confirms that the vertical shear of the zonal

247 wind has the primary role in VIC. The bottom panel of Figure 8 shows the zonal wind

248 term in VIC, but magnetic field-related terms ( $\mathrm{r}$ and $\mathrm{I}$ ) were replaced by their zonal mean

249 to remove the effect of zonal asymmetry in the Earth's magnetic field. Comparing the two

250 bottom panels, we conclude that zonal asymmetry of the Earth's magnetic field does not

251 play a major role in the SW1 and SW3 components of VIC and consequently Es layer

252 formation. Therefore, SW1 and SW3, seen in EsOR, is due to the presence of those

253 components in the neutral atmosphere. 

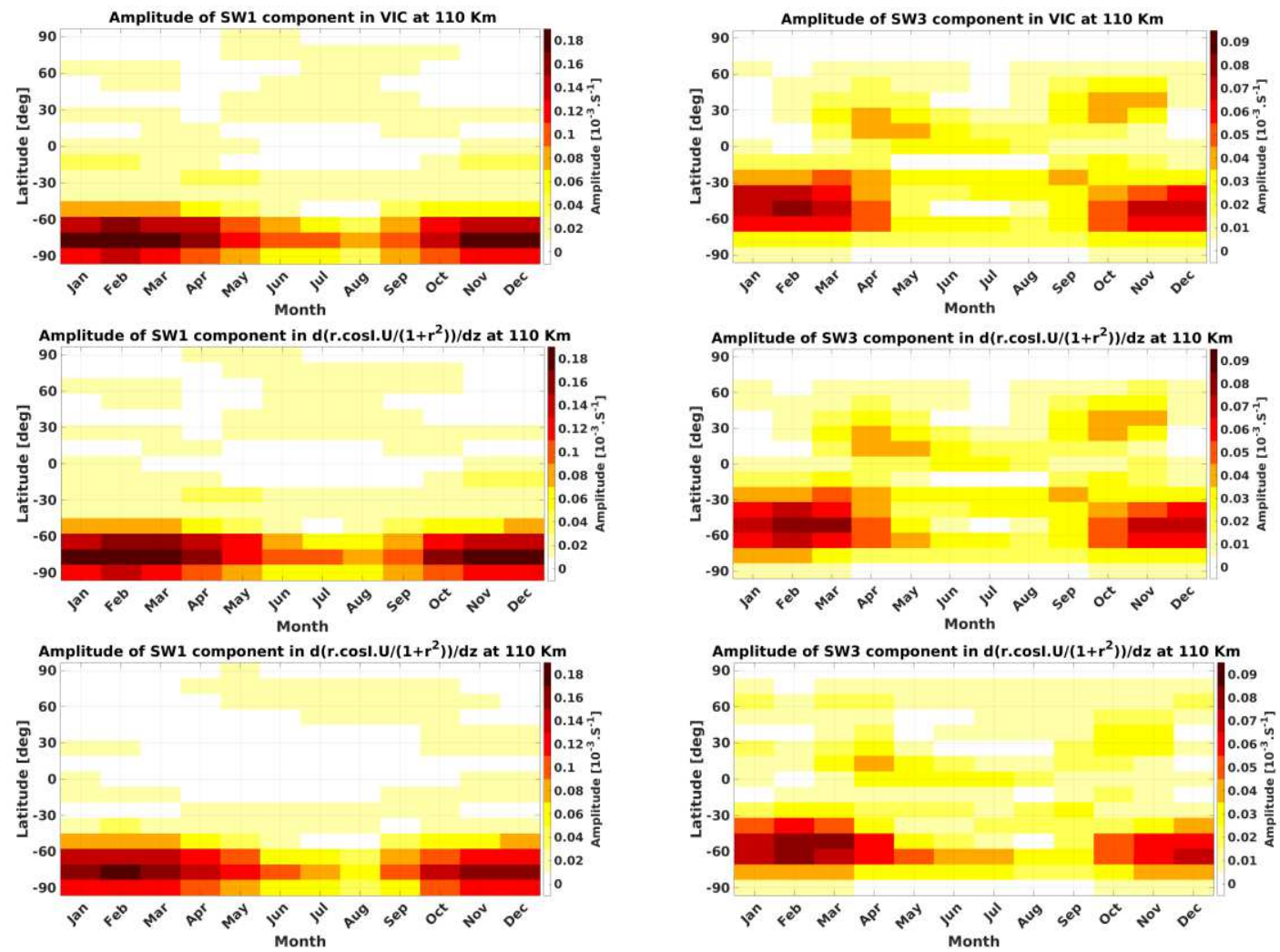

Figure 8 Month-to-month amplitude variation of SW1 (left column) and SW3 (right column) components of VIC (first row), zonal wind term in VIC (second row) and the zonal wind term VIC without the effect of magnetic field zonal asymmetry (third row) at different altitudes

254 The results of this research bring up questions that can be answered in future studies.

255 Comparison of VIC and EsOR tidal components presented in the current paper was based

256 on solar tides. Since GAIA does not include mechanisms to produce lunar tides, further

257 studies using wind models, including lunar tides, could be done to examine lunar tidal

258 components of VIC and their influence on Es layer formation. Furthermore, based on

259 Figure 5, seasonal and latitudinal variations of EsOR tidal components match those in 
260 VIC at higher altitudes. Therefore, another possible future work can be performed using

261 other wind model simulations to see whether the agreement in tidal components of VIC

262 and EsOR would improve.

\section{Conclusions}

264 This study has examined the role of atmospheric tides in Es layer formation using RO

265 data of FORMASAT-3/COSMIC and GAIA model simulations. Tidal analysis has been

266 performed on EsOR and VIC to derive the amplitude of different tidal components.

267 Seasonal variations of migrating and non-migrating tidal components of EsOR and VIC

268 were also studied at different latitudes. The main results are as follows:

269 1- Analyzing 11-year Es, a semidiurnal solar and lunar tidal pattern is visible in the

270 midlatitude EsOR. This confirms previous studies (e.g., Arras et al., 2009; Matsushita,

271 1962) and provides a comprehensive picture of lunar tidal signature in Es occurrence rate,

272 using global RO data.

273 2- Performing spectral analysis on Es data, a qualitative difference between solar and

274 lunar tidal signature in EsOR is evident. Solar tides include both migrating and non- 
275 migrating components, while lunar tides show only the dominance of semidiurnal 276 migrating component at midlatitude.

277 3- Deriving neutral winds from GAIA model simulation, comparisons between vertical

278 ion convergence induced by neutral winds and Es occurrence rate are made. Among all

279 different tidal components, the amplitudes of SW2, DW1, DE2 and SW1 in EsOR show

280 seasonal and latitudinal variations similar to those in the corresponding components of

281 VIC. These agreements suggest that tidal components in EsOR are primarily associated

282 with atmospheric tides.

283 4- SW1 and SW3 are the most dominant non-migrating tidal components of EsOR in

284 southern hemisphere high latitudes. SW1 and SW3 components in EsOR are likely

285 generated by the corresponding tides in neutral atmosphere. Our numerical experiments

286 suggest that the zonal asymmetry of the Earth's Magnetic field does not play a major role

287 in producing SW1 \& SW3 in EsOR. 
288 List of abbreviations

289 GAIA: Ground-to-topside model of Atmosphere and Ionosphere for Aeronomy

290 Es: Sporadic E

291 EsOR: Es Occurrence Rate

292 VIC: Vertical Ion Convergence

293 RO: Radio Occultation

294 GPS: Global Positioning System

295 FORMOSAT-3/COSMIC: FORMOsa SATellite mission-3 / Constellation Observing

296 System for Meteorology, Ionosphere and Climate

297 Availability of data and materials

298 Raw data of GAIA is available at: https://gaia-web.nict.go.jp/data_e.html.

299 The level $1 \mathrm{~b}$ atmPhs radio occultation data from the $\mathrm{F} 3 / \mathrm{C}$ mission are available at

300 COSMIC Data Analysis and Archive Center: https://www.cosmic.ucar.edu/what-we-

301 do/cosmic-1/data/.

302 Competing interests

303 The authors declare that they have no competing interests. 


\section{Authors' contributions}

305 SS did the data analysis and wrote the paper. YY discussed the results and contributed to

306 revise the paper. CA extracted the Es signatures from the SNR of the GPS signal. YM \&

307 HS performed GAIA simulations and the interpretation of the GAIA results. All authors

308 read and approved the final Manuscript.

309 Funding

310 This work was supported in part by JSPS and DFG (grant YA-574-3-1) under the Joint

311 Research Projects LEAD with DFG (JRPs-LEAD with DFG).

\section{Acknowledgements}

313 CA acknowledges support by the DFG Priority Program DynamicEarth, SPP 1788 under

314 grant AR953/1-2. 


\section{References}

316 Andoh, S., Saito, A., Shinagawa, H., \& Ejiri, M. K. (2020). First simulations of day-to-

317 day variability of midlatitude sporadic E layer structures. Earth, Planets and Space, 72(1),

318 1-9. doi: 10.1186/s40623-020-01299-8.

319 Arras, C. (2010). A global survey of sporadic E layers based on GPS Radio occultations

320 by CHAMP, GRACE and FORMOSAT-3/COSMIC (Doctoral dissertation, Deutsches

321 GeoForschungsZentrum GFZ Potsdam). doi: 10.2312/GFZ.b103-10097.

322 Arras, C., Jacobi, C., \& Wickert, J. (2009, June). Semidiurnal tidal signature in sporadic

323 E occurrence rates derived from GPS radio occultation measurements at higher

324 midlatitudes. In Annales geophysicae (Vol. 27, No. 6, pp. 2555-2563). Copernicus

325 GmbH. doi: 10.5194/angeo-27-2555-2009.

326 Arras, C., Jacobi, C., Wickert, J., Heise, S., \& Schmidt, T. (2010). Sporadic E signatures

327 revealed from multi-satellite radio occultation measurements. Advances in Radio

328 Science, 8(GHJ. 1-1/1-), 225-230. doi: 10.5194/ars-8-225-2010. 
329 Arras, C., \& Wickert, J. (2018). Estimation of ionospheric sporadic E intensities from

330 GPS radio occultation measurements. Journal of Atmospheric and Solar-Terrestrial

331 Physics, 171, 60-63. doi: 10.1016/j.jastp.2017.08.006.

332 Arras, C., Wickert, J., Beyerle, G., Heise, S., Schmidt, T., \& Jacobi, C. (2008). A global

333 climatology of ionospheric irregularities derived from GPS radio

334 occultation. Geophysical research letters, 35(14). doi: 10.1029/2008GL034158.

335 Axford, W., \& Cunnold, D. (1966). The wind-shear theory of temperate zone sporadic

336 E. Radio Science, 1(2), 191-197. doi: 10.1002/rds196612191.

337 Christakis, N., Haldoupis, C., Zhou, Q., \& Meek, C. (2009, March). Seasonal variability

338 and descent of mid-latitude sporadic E layers at Arecibo. In Annales geophysicae (Vol.

339 27, No. 3, pp. 923-931). Copernicus GmbH. doi: 10.5194/angeo-27-923-2009.

340 Chu, Y.-H., Wang, C., Wu, K., Chen, K., Tzeng, K., Su, C.-L., Feng, W., \& Plane, J.

341 (2014). Morphology of sporadic E layer retrieved from COSMIC GPS radio occultation

342 measurements: Wind shear theory examination. Journal of Geophysical Research: Space

343 Physics, 119(3), 2117-2136. doi: 10.1002/2013JA019437. 
344 Finlay, C. C., Maus, S., Beggan, C., Bondar, T., Chambodut, A., Chernova, T., Chulliat,

345 A., Golovkov, V., Hamilton, B., \& Hamoudi, M. (2010). International geomagnetic

346 reference field: the eleventh generation. Geophysical Journal International, 183(3), 1216-

347 1230. doi: 10.1111/j.1365-246X.2010.04804.x.

348 Forbes, J., Zhang, X., Palo, S., Russell, J., Mertens, C., \& Mlynczak, M. (2008). Tidal

349 variability in the ionospheric dynamo region. Journal of Geophysical Research: Space

350 Physics, 113(A2). doi: 10.1029/2007JA012737.

351 Fytterer, T., Arras, C., Hoffmann, P., \& Jacobi, C. (2014). Global distribution of the

352 migrating terdiurnal tide seen in sporadic E occurrence frequencies obtained from GPS

353 radio occultations. Earth, Planets and Space, 66(1), 1-9. doi: 10.1186/1880-5981-66-79.

354 Fytterer, T., Arras, C., \& Jacobi, C. (2013). Terdiurnal signatures in sporadic E layers at

355 midlatitudes. Advances in Radio Science, 11(YSA), 333-339. doi: 10.5194/ars-11-333-

3562013.

357 Haldoupis, C. (2011). A tutorial review on sporadic E layers. In: Aeronomy of the Earth's

358 Atmosphere and Ionosphere, 381-394. 
359 Haldoupis, C. (2012). Midlatitude sporadic E. A typical paradigm of atmosphere360 ionosphere coupling. Space Science Reviews, 168(1), 441-461. doi: 10.1007/s11214$361 \quad 011-9786-8$.

362 Haldoupis, C., \& Pancheva, D. (2002). Planetary waves and midlatitude sporadic E 363 layers: Strong experimental evidence for a close relationship. Journal of Geophysical 364 Research: Space Physics, 107(A6), SIA 3-1-SIA 3-6. doi: 10.1029/2001JA000212.

365 Haldoupis, C., \& Pancheva, D. (2006). Terdiurnal tide-like variability in sporadic E 366 layers. Journal of Geophysical Research: Space Physics, 111(A7). doi: $367 \quad 10.1029 / 2005 J A 011522$.

368 Haldoupis, C., Pancheva, D., \& Mitchell, N. (2004). A study of tidal and planetary wave 369 periodicities present in midlatitude sporadic E layers. Journal of Geophysical Research:

$370 \quad$ Space Physics, 109(A2). doi: 10.1029/2003JA010253.

371 Haldoupis, C., Pancheva, D., Singer, W., Meek, C., \& MacDougall, J. (2007). An 372 explanation for the seasonal dependence of midlatitude sporadic E layers. Journal of 373 Geophysical Research: Space Physics, 112(A6). doi: 10.1029/2007JA012322. 
374 Igarashi, K., Nakamura, M., Wilkinson, P., Wu, J., Pavelyev, A., \& Wickert, J. (2001).

375 Global sounding of sporadic $E$ layers by the GPS/MET radio occultation

376 experiment. Journal of Atmospheric and Solar-Terrestrial Physics, 63(18), 1973-

377 1980. doi: 10.1016/S1364-6826(01)00063-3.

378 Jacobi, C., Arras, C., Geißler, C., \& Lilienthal, F. (2019, May). Quarterdiurnal signature

379 in sporadic E occurrence rates and comparison with neutral wind shear. In Annales

380 Geophysicae (Vol. 37, No. 3, pp. 273-288). Copernicus GmbH. doi: 10.5194/angeo-37-

$381 \quad 273-2019$.

382 Jin, H., Miyoshi, Y., Fujiwara, H., Shinagawa, H., Terada, K., Terada, N., Ishii, M.,

383 Otsuka, Y., \& Saito, A. (2011). Vertical connection from the tropospheric activities to the

384 ionospheric longitudinal structure simulated by a new Earth's whole atmosphere-

385 ionosphere coupled model. Journal of Geophysical Research: Space

386 Physics, 116(A1). doi: 10.1029/2010JA015925.

387 Liu, Y., Zhou, C., Tang, Q., Li, Z., Song, Y., Qing, H., Ni, B., \& Zhao, Z. (2018). The

388 seasonal distribution of sporadic E layers observed from radio occultation measurements 
389 and its relation with wind shear measured by TIMED/TIDI. Advances in Space 390 Research, 62(2), 426-439. doi: 10.1016/j.asr.2018.04.026.

391 Liu, Z., Fang, H., Yue, X., \& Lyu, H. (2021). Wavenumber-4 Patterns of the Sporadic E 392 Over the Middle-and Low-Latitudes. Journal of Geophysical Research: Space 393 Physics, 126(8), e2021JA029238. doi: 10.1029/2021JA029238.

394 Lühr, H., \& Manoj, C. (2013, August). The complete spectrum of the equatorial electrojet 395 related to solar tides: CHAMP observations. In Annales Geophysicae (Vol. 31, No. 8, pp. 396 1315-1331). Copernicus GmbH. Doi: 10.5194/angeo-31-1315-2013.

397 Macleod, M. A. (1966). Sporadic E theory. I. Collision-geomagnetic equilibrium. Journal 398 of Atmospheric Sciences, 23(1), 96-109. doi: 10.1175/1520-0469(1966)023.

399 Mathews, J. (1998). Sporadic E: current views and recent progress. Journal of 400 Atmospheric and Solar-Terrestrial Physics, 60(4), 413-435. doi: 10.1016/S1364401 6826(97)00043-6.

402 Mathews, J. D., \& Bekeny, F. (1979). Upper atmosphere tides and the vertical motion of 403 ionospheric sporadic layers at Arecibo. Journal of Geophysical Research: Space 404 Physics, 84(A6), 2743-2750. doi: 10.1029/JA084iA06p02743. 
405 Matsushita, S. (1952). Semidiurnal lunar variations in the sporadic-E. Journal of 406 geomagnetism and geoelectricity, 4(1), 39-40. doi: 10.5636/jgg.4.39.

407 Matsushita, S. (1957). Lunar effects on the equatorial Es. Journal of Atmospheric and 408 Terrestrial Physics, 10(3), 163-165. doi: 10.1016/0021-9169(57)90097-1.

409 Matsushita, S. (1962). Lunar tidal variations of sporadic E. In Ionospheric Sporadic (pp.

410 194-214). Elsevier. doi: 10.1016/B978-0-08-009744-2.50021-7.

411 Matsushita, S. (1967). Lunar tides in the ionosphere. In Geophysik III/Geophysics III (pp.

412 547-602). Springer, Berlin, Heidelberg. doi: 10.1007/978-3-642-46082-1_2.

413 Miyoshi, Y., Pancheva, D., Mukhtarov, P., Jin, H., Fujiwara, H., \& Shinagawa, H. (2017).

414 Excitation mechanism of non-migrating tides. Journal of Atmospheric and Solar-

415 Terrestrial Physics, 156, 24-36. doi: 10.1016/j.jastp.2017.02.012.

416 Oikonomou, C., Haralambous, H., Haldoupis, C., \& Meek, C. (2014). Sporadic E tidal 417 variabilities and characteristics observed with the Cyprus Digisonde. Journal of 418 Atmospheric and Solar-Terrestrial Physics, 119, 173-183. doi: $419 \quad 10.1016 /$ j.jastp.2014.07.014. 
420 Qiu, L., Zuo, X., Yu, T., Sun, Y., \& Qi, Y. (2019). Comparison of global morphologies

421 of vertical ion convergence and sporadic $\mathrm{E}$ occurrence rate. Advances in Space

422 Research, 63(11), 3606-3611. doi: 10.1016/j.asr.2019.02.024.

423 Pancheva, D., Haldoupis, C., Meek, C., Manson, A., \& Mitchell, N. (2003). Evidence of

424 a role for modulated atmospheric tides in the dependence of sporadic E layers on

425 planetary waves. Journal of Geophysical Research: Space Physics, 108(A5). doi:

$426 \quad 10.1029 / 2002 J A 009788$.

427 Richmond, A. D. (2017). Ionospheric electrodynamics. In Handbook of Atmospheric

428 Electrodynamics, Volume II (pp. 249-290). CRC Press.

429 Shinagawa, H., Miyoshi, Y., Jin, H., \& Fujiwara, H. (2017). Global distribution of neutral

430 wind shear associated with sporadic E layers derived from GAIA. Journal of Geophysical

431 Research: Space Physics, 122(4), 4450-4465. doi: 10.1002/2016JA023778.

432 Stening, R. J. (1999, September). The lunar tide in sporadic E. In Annales

433 Geophysicae (Vol. 17, No. 10, pp. 1344-1351). Springer-Verlag. doi: 10.1007/s00585- 
435 Tarpley, J., \& Matsushita, S. (1971). The lunar tide in $f$ bEs. Radio Science, 6(2), 191-

436 196. doi: 10.1029/RS006i002p00191.

437 Tarpley, J., \& Matsushita, S. (1972). Lunar influences on sporadic E. Radio Science, 7(3),

438 411-416. doi: 10.1029/RS007i003p00411.

439 Voiculescu, M., Haldoupis, C., \& Schlegel, K. (1999). Evidence for planetary wave

440 effects on midlatitude backscatter and sporadic E layer occurrence. Geophysical research

441 letters, 26(8), 1105-1108. doi: 10.1029/1999GL900172.

442 Whitehead, J. (1961). The formation of the sporadic-E layer in the temperate

443 zones. Journal of Atmospheric and Terrestrial Physics, 20(1), 49-58. doi: 10.1016/0021-

444 9169(61)90097-6.

445 Whitehead, J. (1970). Production and prediction of sporadic E. Reviews of

446 Geophysics, 8(1), 65-144. doi: 10.1029/RG008i001p00065.

447 Whitehead, J. (1989). Recent work on midlatitude and equatorial sporadic-E. Journal of

448 Atmospheric and Terrestrial Physics, 51(5), 401-424. doi: 10.1016/0021-

449 9169(89)90122-0. 
450 Wu, D. L., Ao, C. O., Hajj, G. A., de La Torre Juarez, M., \& Mannucci, A. J. (2005).

451 Sporadic E morphology from GPS-CHAMP radio occultation. Journal of Geophysical

452 Research: Space Physics, 110(A1). doi: 10.1029/2004JA010701.

453 Yeh, W. H., Liu, J. Y., Huang, C. Y., \& Chen, S. P. (2014). Explanation of the sporadic-

454 E layer formation by comparing FORMOSAT-3/COSMIC data with meteor and wind

455 shear information. Journal of Geophysical Research: Atmospheres, 119(8), 4568-4579.

456 doi: 10.1002/2013JD020798. 


\section{Supplementary Files}

This is a list of supplementary files associated with this preprint. Click to download.

- EPSgraphic.png 